\title{
Aplikasi TEMPO Sebagai Metode Pengendalian TB dan TB HIV di Desa Punggur Kapuas dan Sungai Kakap, Kabupaten Kubu Raya
}

\author{
Djoko Priyono ${ }^{1}$, Arina Nurfianti ${ }^{2}$, Faisal Kholid Fahdi ${ }^{3}$, \\ M. Ali Maulana ${ }^{4}$, Nita Yulanda Arisanti ${ }^{5}$ \\ 1,2,3,4,5 Prodi Keperawatan, Fakultas Kedokteran, Universitas Tanjungpura \\ Jl. Prof. Dr. H. Hadari Nawawi, Kota Pontianak, Kalimantan Barat 78124 \\ Email:djokopri07@gmail.com
}

\begin{abstract}
Abstrak
Tuberkulosis merupakan penyakit menular yang menyebabkan kematian ketiga setelah penyakit kardiovaskular dan penyakit saluran pernafasan. Prevalensi yang semakin meningkat memerlukan kegiatan skrining yang sistematis untuk mencegah meluasnya penyakit menular TB sekaligus mendukung program pemerintah dengan memasimalkan peran tenaga kesehatan sebagai garda utama dan memberdayakan masyarakat dalam upaya saling membantu mengurangi hingga mengeliminasi penyakit TB. Salah satu upaya yang dapat dilakukan dengan mengguankan strategi TEMPO (TEMukan pasien secepatnya, Pisahkan secara aman, Obati secara tepat). Metode ini mudah untuk diterapkan dan tidak membutuhkan biaya yang besar. Dengan metode ini pula akan mengurangi resiko penularan kasus TB dan TB Resistan obat yang belum teridentifikasi. Kegiatan ini dilakukan di desa punggur Kapuas dan sungai Kakap, Kabupaten Kubu Raya dengan jumlah peserta sebanyak 100 orang. Kegiatan yang dilakukan berupa skrining, penyuluhan dan kegiatan pengkaderan. Hasil kegiatan menunjukkan 75 orang dinyatakan negatif mengalami TB.
\end{abstract}

\section{Kata Kunci: TEMPO, Pengendalian TB, TB HIV}

\section{Pendahuluan}

Penyakit TBC merupakan penyakit menular yang menyebabkan kematian, dan merupakan penyebab kematian ketiga di Indonesia. Hasil Survei Kesehatan Rumah Tangga (SKRT) tahun 2001 penyakit TBC merupakan penyebab kematian ketiga setelah penyakit kardiovaskular dan penyakit saluran pernafasan pada semua kelompok usia, bahkan peringkat pertama penyebab kematian penyakit menular. Dalam prevalensi kejadian TB Paru, jika TB Paru terjadi pada 100/100.000 populasi maka atau lebih maka skrining TB paru yang sistematis perlu dipertimbangkan pada komunitas tersebut, selain juga faktor risiko seperti petugas kesehatan dan kelompok individu yang memiliki risiko (WHO, 2014).

Sasaran srategi Nasional pengendalian TB Paru hingga 2014 mengacu pada rencana strategis Kementrian Kesehatan 2009-2014 yaitu menurunkan prevalensi TB dari 235 per 100.000 penduduk menjadi 224 per 100.000 penduduk. Saat ini diperkirakan ada 1 dari setiap 3 kasus TB yang masih belum terdeteksi oleh program. Angka prevalensi kejadian TB di Kalimantan Barat pada data Februari 2015 adalah 120 orang per 100.000 penduduk, sementara 
ISSN : $2620-4665$ (print)

ISSN : $2620-4673$ (online)

Website : http://jurnal.untan.ac.id/index.php/JPLP2KM

angka keberhasilan pengobatan TB per tahun 2013 di Provinsi Kalimantan Barat adalah $83 \%$ (Kemenkes RI, 2015).

Dalam mencegah meluasnya penyakit menular TB pemerintah mencanangkan program dengan memasimalkan peran tenaga kesehatan sebagai garda utama dan memberdayakan masyarakat dalam upaya saling membantu mengurangi hingga mengeliminasi penyakit TB. Salah satu upaya yang dapat dilakukan dengan mengguankan strategi TEMPO (TEMukan pasien secepatnya, Pisahkan secara aman, Obati secara tepat). Penerapan mudah dan tidak membutuhkan biaya yang besar, dan idela untuk diterapkan. Dengan menggunakan strategi TEMPO akan mengurangi resiko penularan kasus TB dan TB Resistan obat yang belum teridentifikasi.

Desa Punggur Kabupaten Kubu Raya merupakan desa binaan Prodi Keperawatan Fakultas Kedokteran Untan sejak tahun 2017 setelah Desa Jawa Tengah, Kabupaten Kubu Raya. Di dalam wilayah Desa Punggur telah dilaksanakan kegiatan pengabdian kesehatan pada masyarakat melalui pembinaan baik dari mahasiswa keperawatan maupun dosen. Desa yang telah dibina di Kecamatan Punggur adalah Desa Punggur Besar dan Desa Punggur Kecil.

Berdasarkan studi pendahuluan yang dilakukan tim didapatkan laporan bahwa di Kecamatan Punggur terdapat 3 orang yang dilaporkan mengalami TB. Berdasarkan data ini kepala desa mengharapkan adanya peran dari institusi pendidikan khususnya Prodi Keperawatan Fakultas Kedokteran Universitas Tanjungpura untuk mengadakan kegiatan promotif dan preventif agar tidak terjadi penyebaran TB dan yang telah mengalami TB tidak mengalami kondisi yang lebih buruk.

Para masyarakat khususnya di desa-desa belum ada dilakukan pendidikan pencegahan penyakit menular yang komprehensif yang dapat memastikan seseorang dapat terhindar dari mudahnya tertular penyakit, menumbuhkan kesadaran pada prinsip pereventif hingga kuratif. Maka dari itu diperlukan suatu kegiatan nyata untuk memberikan pendidikan pencegahan penyakit menular dan penemuan kejadian kasus di wilayah Kecamatan Punggur, Kabupaten Kubu Raya.

\section{Tinjauan Pustaka}

\section{a. Tuberkulosis}

Tuberkolosis adalah suatu penyakit menular yang disebabkan oleh kuman dari kelompok Mycobacterium yaitu Mycobacterium tubercolosis (M.tb). Beberapa spesies Mycobacterium, antara lain: M. tubercolosis, M. Africanum, M. bovis, M. leprea dsb, yang juga disebut dengan bakteri tahan asam (BTA). (Murtiwi, 2006)

\section{1) Klasifikasi berdasarkan organ tubuh yang terkena:}

a) Tuberkulosis paru. Tuberkulosis paru adalah tuberkulosis yang menyerang jaringan (parenkim) paru. tidak termasuk pleura (selaput paru) dan kelenjar pada hilus. 
b) Tuberkulosis ekstra paru. Tuberkulosis yang menyerang organ tubuh lain selain paru, misalnya pleura, selaput otak, selaput jantung (pericardium), kelenjar lymfe, tulang, persendian, kulit, usus, ginjal, saluran kencing, alat kelamin, dan lain-lain.

2) Klasifikasi berdasarkan tipe pasien ditentukan berdasarkan riwayat pengobatan sebelumnya

a) Kasus baru. Pasien yang belum pernah diobati dengan OAT atau sudah pernah menelan OAT kurang dari satu bulan (4 minggu).

b) Kasus kambuh (relaps). Pasien tuberkulosis yang sebelumnya pernah mendapat pengobatan tuberkulosis dan telah dinyatakan sembuh tetapi kambuh lagi.

c) Kasus setelah putus berobat (default). Pasien yang telah berobat dan pututs 2 bulan atau lebih dengan BTA positif

d) Kasus setelah gagal (failure). Pasien yang hasil pemeriksaan dahaknya tetap positif atau kembali menjadi positif pada bulan kelima atau lebih selama pengobatan.

e) Kasus lain. Semua kasus yang tidak memenuhi ketentuan diatas, dalam kelompok ini termasuk kasus kronik, yaitu pasien dengan hasil pemeriksaan masih BTA positif setelah selesai pengobatan ulangan.

\section{b. Tanda dan Gejala}

Tanda-tanda yang di temukan pada pemeriksaan fisik tergantung luas dan kelainan struktural paru. Pada lesi minimal, pemeriksaan fisis dapat normal atau dapat ditemukan tanda konsolidasi paru utamanya apeks paru. Tanda pemeriksaan fisik paru tersebut dapat berupa: fokal fremitus meingkat, perkusi redup, bunyi napas bronkovesikuler atau adanya ronkhi terutama di apeks paru. Pada lesi luas dapat pula ditemukan tanda-tanda seperti: deviasi trakea ke sisi paru yang terinfeksi, tanda konsolidasi, suara napas amporik pada cavitas atau tanda adanya penebalan pleura.

1) Gejala sistemik/umum

a) Penurunan nafsu makan dan berat badan.

b) Perasaan tidak enak (malaise), lemah.

c) Demam tidak terlalu tinggi yang berlangsung lama, biasanya dirasakan malam hari disertai keringat malam. Kadang-kadang serangan demam seperti influenza dan bersifat hilang timbul.

2) Gejala khusus

a) Bila terjadi sumbatan sebagian bronkus (saluran yang menuju ke paru-paru) akibat penekanan kelenjar getah bening yang membesar, akan menimbulkan suara "mengi", suara nafas melemah yang disertai sesak.

b) Jika ada cairan dirongga pleura (pembungkus paru-paru), dapat disertai dengan keluhan sakit dada.

\section{c. Pemeriksaan dahak mikroskopis}

Pemeriksaan dahak berfungsi untuk menegakkan diagnosis, menilai 
ISSN : $2620-4665$ (print)

ISSN : $2620-4673$ (online)

Website : http://jurnal.untan.ac.id/index.php/JPLP2KM

keberhasilan pengobatan dan menentukan potensi penularan. Pemeriksaan dahak untuk penegakan diagnosis dilakukan dengan mengumpulkan 3 spesimen dahak yang dikumpulkan dalam dua hari kunjungan yang berurutan sewaktu-pagisewaktu (SPS)

1) $\mathbf{S}$ (Sewaktu); dahak ditampung pada saat terduga pasien TB berkunjung pertama kali. Pada saat pulang, terduga pasien membawa sebuah pot dahak untuk menampung dahal pagi pada hari kedua

2) P (Pagi); dahak ditampung dirumah pada pagi hari kedua, segera stelah bangun tidur

3) S (Sewaktu); dahak ditampung pada hari kedua, saat menyerahkan dahak pagi

\section{d. Penetapan diagnosis TB pada pasien dewasa}

1) Pemeriksaan bakteriologis terlebih dahulu (pemeriksaan mikroskopis langsung, biakan dan test cepat)

2) Apabila negatif maka dilakukan pemeriksaan penunjang (foto toraks)

3) Sarana terbatas; penegakan diagnosis secara klinis dilakukan setelah pemberian terapi antibiotik spektrum luas (Non OAT dan Non Kuinolon) yang tidak memberikan perbaikan klinis

\section{e. Pemeriksaan Dahak Mikroskopis Langsung}

1) Uji dahak SPS

2) Ditetapkan sebagai pasien TB apabila minimal 1 (satu) dari pemeriksaan contoh uji dahak SPS hasilnya BTA positif

\section{f. Pencegahan dan Pengendalian Infeksi Tuberkolosis}

Penularan utama TB adalah melalui cara dimana kuman TB (Mycobacterium tuberculosis) tersebar melalui diudara melalui percik renik dahak saat pasien TB paru atau TB laring batuk, berbicara, menyanyi maupun bersin. Percik renik tersebut berukuran antara 1-5 mikron sehingga aliran udara memungkinkan percik renik tetap melayang diudara untuk waktu yang cukup lama dan menyebar keseluruh ruangan. Kuman TB pada umumnya hanya ditularkan melalui udara, bukan melalui kontak permukaan.

Infeksi terjadi apabila seseorang yang rentan menghirup percik renik yang mengandung kuman TB melalui mulut atau hidung, saluran pernafasan atas, bronchus hingga mencapai alveoli. Mencegah penularan tuberkulosis pada semua orang yang terlibat dalam pemberian pelayanan pada pasien TB harus menjadi perhatian utama. Penatalaksanaan Pencegahan dan Pengendalian Infeksi (PPI) TB bagi petugas kesehatan sangatlah penting peranannya untuk mencegah tersebarnya kuman TB ini.

Salah satu risiko utama terkait dengan penularan TB di tempat pelayanan kesehatan adalah yang berasal dari pasien TB yang belum teridentifikasi. Akibatnya pasien tersebut belum sempat dengan segera diperlakukan sesuai kaidah PPI TB yang tepat. 
Salah satu upaya yang dapat dilakukan dengan mengguankan strategi TEMPO (TEMukan pasien secepatnya, Pisahkan secara aman, Obati secara tepat). Penerapan mudah dan tidak membutuhkan biaya yang besar, dan idela untuk diterapkan. Dengan menggunakan strategi TEMPO akan mengurangi resiko penularan kasus TB dan TB Resistan obat yang belum teridentifikasi.

Untuk mencegah adanya kasus TB dan TB resistan obat yang tidak terdiagnosis, dilaksanakan strategi TEMPO dengan skrining bagi semua pasien dengan gejala batuk

\section{g. Langkah-Langkah Strategi TEMPO sebagai berikut:}

1) Temukan pasien secepatnya.

Strategi TEMPO secara khusus memanfaatkan petugas surveilans batuk untuk mengidentifikasi terduga TB segera mencatat di TB 06 dan mengisi TB 05 dan dirujuk ke laboratorium.

\section{2) Pisahkan secara aman.}

Petugas surveilans batuk segera mengarahkan pasien yang batuk ke tempat khusus dengan area ventilasi yang baik, yang terpisah dari pasien lain,serta diberikan masker. Untuk alasan kesehatan masyarakat, pasien yang batuk harus didahulukan dalam antrian (prioritas).

3) Obati secara tepat.

Pengobatan merupakan tindakan paling penting dalam mencegah penularan TB kepada orang lain. Pasien TB dengan terkonfirmasi bakteriologis, segera diobati sesuai dengan panduan nasional sehingga menjadi tidak infeksius.

\section{Metode}

Kegiatan Pengabdian Masyarakat ini dilakukan melalui beberapa bentuk kegiatan sesuai dengan masalah penyakit menular yang didapat melalui identifikasi masalah serta mendapat data dan masukan dari puskesmas. Kegiatan yang dilakukan didukung oleh beberapa pihak yang berkepentingan. Kegiatan ini juga merupakan rangkaian kegiatan penguatan kesehatan masyarakat setempat dalam menanggulangi TB Paru sebagai penyakit menular. Kegiatan ini berupa:

a. Mengidentifikasi masalah kesehatan di masyarakat

b. Menyimpulkan hasil pengkajian

c. Bekerjasama dengan Puskesmas setempat dan UP4 Provinsi Kalbar

d. Skrining pasien dengan risiko TB Paru

e. Skrining kelompok masyarakat dengan risiko HIV melalui VCT bekerjasama dengan Puskesmas dan UP4 Provinsi Kalbar

f. Skrining risiko TB Paru pada individu dengan HIV Positif

g. Penyuluhan kesehatan dan pendampingan warga sesuai masalah yang didapat

h. Pengkaderan pada beberapa warga 
ISSN : $2620-4665$ (print)

ISSN : $2620-4673$ (online)

Website : http://jurnal.untan.ac.id/index.php/JPLP2KM

\section{Hasil dan Pembahasan}

\section{a. Persiapan Kegiatan}

Persiapan dilakukan pada bulan April 2019. Pada tahap persiapan ini tim melakukan koordinasi dengan mahasiswa Program Studi Profesi Ners Angkatan VI yang sedang menjalani stase Keperawatan Komunitas di Desa Punggur Kapuas dan Puskesmas Punggur. Koordinasi selanjutnya dilakukan dengan pihak puskesmas punggur untuk mendapatkan data pasien-pasien yang akan dilakukan skrining, pemeriksaan BTA, dan kesediaan pemegang program TB untuk memberikan penyuluhan kepada masyarakat. Selanjutnya tim melakukan koordinasi dengan mahasiswa untuk melakukan pemetaan lokasi dan petugas yang akan melakukan kegiatan skrining. Dalam melakukan kegiatan persiapan ini tim tidak menemukan kendala yang cukup berarti sehingga dapat dilanjutkan dengan pelaksanaan kegiatan pada bulan Mei 2019.

\section{b. Pelaksanaan Kegiatan}

Pelaksanaan kegiatan skrining dilakukan selama 2 bulan sejak bulan Mei hingga bulan Juni. Kegiatan skrining cukup memakan waktu yang cukup lama dikarenakan harus menempuh medan yang cukup sulit agar sampai kerumah pasien. Selain itu, terdapat satu dusun (dusun selat kering) yang mengharuskan tim menggunakan motor air agar sampai ke lokasi tujuan. Selama kegiatan skrining ini tim mendapatkan sambutan yang baik oleh pasien dan keluarga sehingga tim dapat menyelesaikan kegiatan skrining kepada 100 orang responden. Kegiatan ini diakhiri dengan melakukan kontrak waktu untuk pertemuan berikutnya.
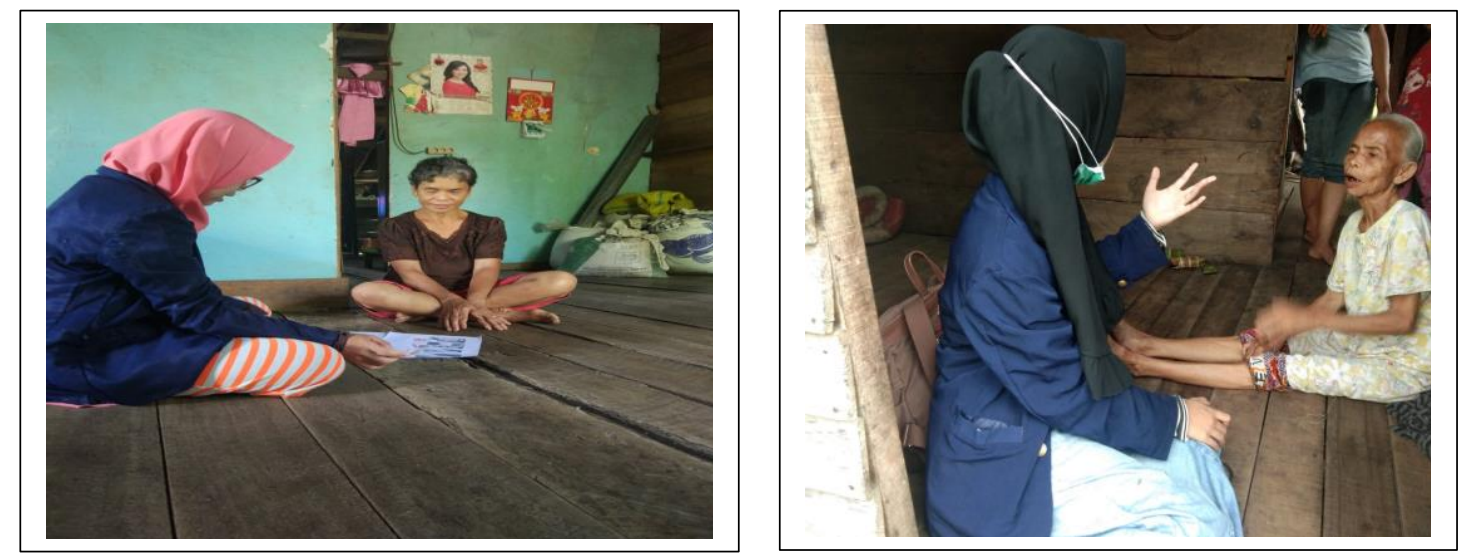

Gambar 1. Kegiatan Skrining Pasien TB 

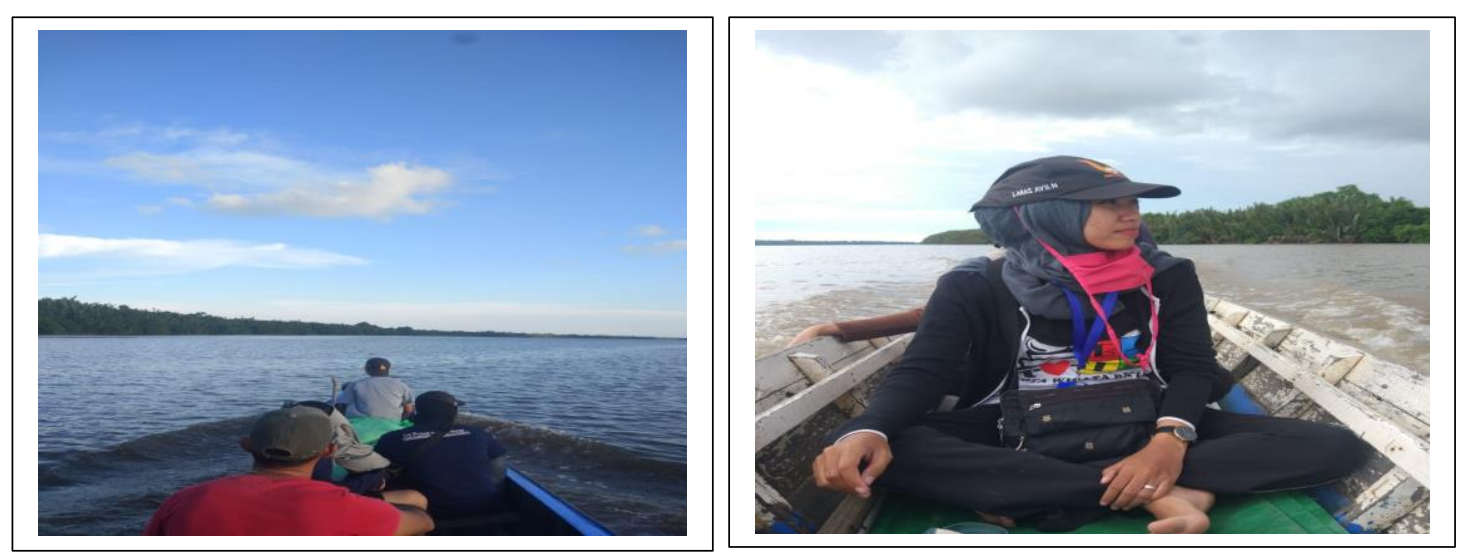

Gambar 2. Perjalanan Menuju Dusun Selat Kering

Setelah dilakukan kegiatan skrining, tim dibantu mahasiswa Program Studi Profesi Ners Angkatan VI melakukan tabulasi dan validasi responden dan didapatkan sebanyak 75 responden perlu dilakukan pemeriksaan sputum.
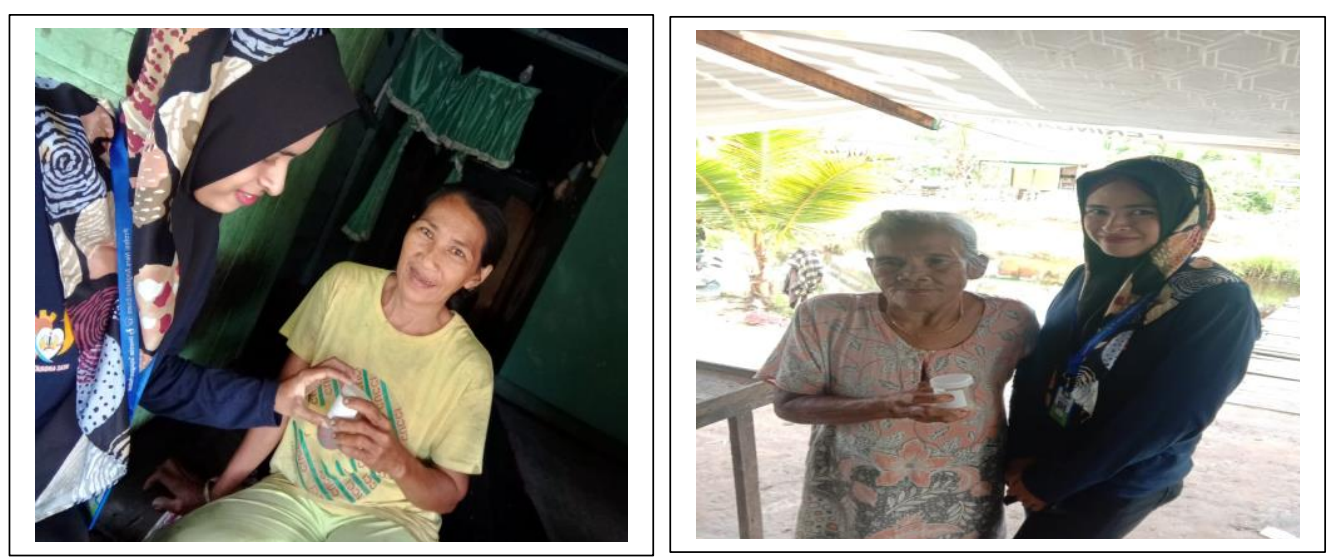

Gambar 3. Responden Memegang Pot Sputum

Pelaksanaan pemeriksaan sputum dilakukan sebnyak 3 kali menggunakan konsep S (Sewaktu); dahak ditampung pada saat terduga pasien TB berkunjung pertama kali. Pada saat pulang, terduga pasien membawa sebuah pot dahak untuk menampung dahal pagi pada hari kedua P (Pagi); dahak ditampung dirumah pada pagi hari kedua, segera stelah bangun tidur S (Sewaktu); dahak ditampung pada hari kedua, saat menyerahkan dahak pagi. Sputum yang telah ditampung di dalam pot langsung dibawa ke Laboratorium TBC di Puskesmas Punggur.

Kegiatan selanjutnya adalah melakukan penyuluhan TB dan pembentukan kader peduli TB serta menggerakkan keluarga untuk menjadi Pengawas Minum Obat (PMO) terhadap anggota keluarganya yang sedang menjalani pengobatan. Selain melakukan penyuluhan dan pembentukan kader, tim juga mengadakan kegiatan pemeriksaan dan pengobatan gratis bagi respondan dan keluarga yang telah dilakukan skrining. Kegiatan ini berlangsung sejak pukul 08.00 - 16.00. Kendala yang tim hadapi dalam kegiatan ini 
ISSN : $2620-4665$ (print)

ISSN : $2620-4673$ (online)

Website : http://jurnal.untan.ac.id/index.php/JPLP2KM

adalah responden dan keluarga masih banyak yang belum memiliki kendaraan, sehingga tim dibantu dengan mahasiswa harus melakukan penjemputan agar responden dan keluarga dapat sampai kelokasi kegiatan.
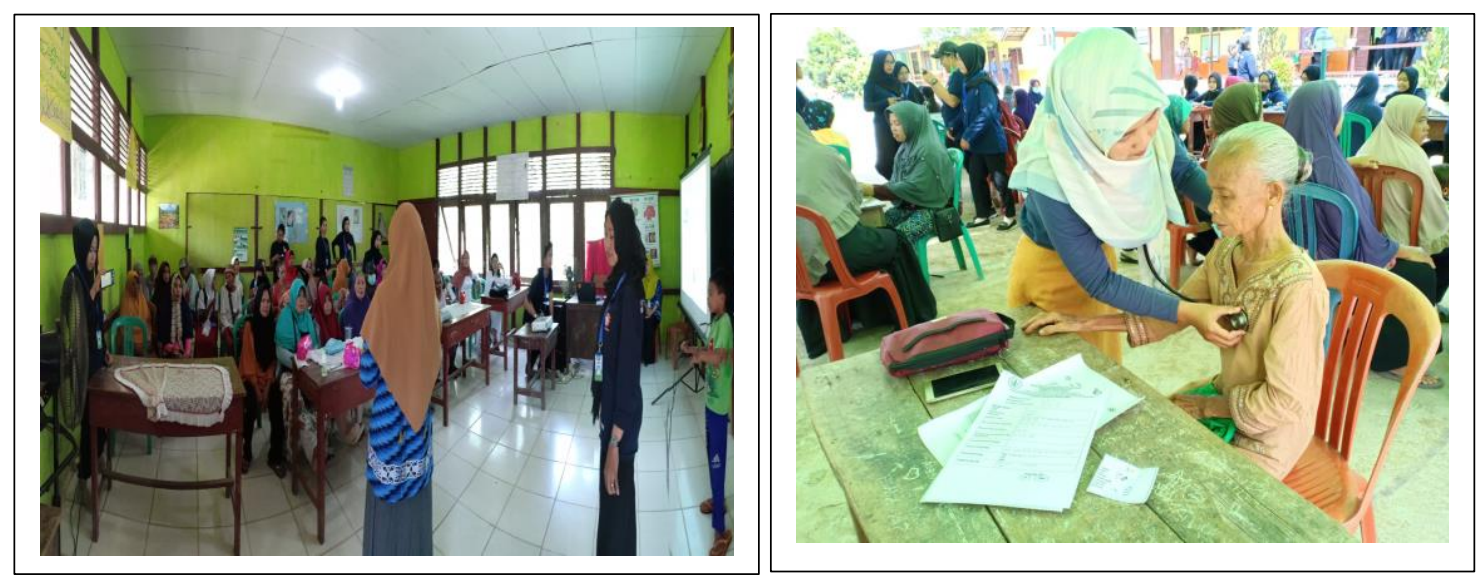

\section{Gambar 4. Kegiatan Penyuluhan dan Pengobatan Gratis}

Berdasarkan dari hasil pemeriksaan laboratorium dinyatakan 75 orang negative (-) mengalami TBC. Hal ini dikeranakan terdapat pasien yang semula positif (+) TBC telah menyelesaikan pengobatan dengan baik. Selain itu juga tim tidak menemukan penyimpangan seksual terhadap 75 orang yang telah dilakukan pemeriksaan sputum, sehingga tim tidak melakukan pemeriksaan VCT yang telah diagendakan sebelumnya. Kegiatan ditutup dengan memberikan laporan kepada pihak puskesmas Punggur dan penyerahan cinderamata.

\section{Kesimpulan dan Rekomendasi}

Dari seluruh rangkaian kegiatan ini, maka dapat ditarik kesimpulan sebanyak 75 orang negatif mengalami TBC dan metode TEMPO sebagai metode yang efektif dalam melakukan pengendalian penularan TB di masyarakat. Selain dilakukan kegiatan skrining diperlukan juga upaya promotif lain seperti melakukan penyuluhan kesehatan yang berkelanjutan agar tumbuh kesadaran di masyarakat untuk selalu melakukan pola hidup sehat dalam kesehariannya. Kegiatan skrining ini sebaiknya dilakukan secara rutin dan masyarakat berperan aktif dalam menekan angka penularan TBC.

\section{Ucapan Terima Kasih}

Terima kasih disampaikan kepada Universitas Tanjungpura memalaui Dana DIPA tahun anggaran 2019 yang telah membiayai pelaksanaan kegiaatan PKM ini, Puskesmas Punggur yang telah bersedia dan menyambut baik kegiatan ini, Kepala Desa serta jajaran Desa Punggur Kapuas yang telah memberikan pengarahan dan bantuan kepada tim pelaksana, serta mahasiswa Program Studi Profesi Ners Angkatan VI Fakultas Kedokteran, Universitas Tanjungpura Poantianak atas partisipasinya dalam kegiatan ini. 


\section{Daftar Pustaka}

Kemenkes RI. 2015. TB: Temukan Obati Sampai Sembuh. Pusat Data dan Informasi Kementrian Kesehatan RI.

Kementrian Kesehatan RI (2014). Pedoman Nasional Pengendalian Tuberkolosis. Direktorat Jenderal Pengendalian Penyakit dan Penyehatan Lingkungan; Jakarta

Murtiwi. 2006. Keberadaan Pengawas Minum Obat (PMO) Pasien Tuberkulosis Paru di Indonesia. jki.ui.ac.id/index.php/jki/article/download/167/pdf_89

WHO. 2013. Systematic screening for active tuberculosis. Principles and Recommendation. WHO Document Production Services, Geneva, Switzerland 